\title{
ENVELHECIMENTO E CONSUMO: \\ AS REPRESENTAÇÕES DA VELHICE FEMININA \\ NO DISCURSO MIDIÁTICO
}

Alberto Malheiros Junior

Silvane Aparecida de Freitas ${ }^{2}$

resumo

Este trabalho se propôs a discutir a velhice feminina, por meio da análise de um artigo presente na revista Veja, do mês de agosto de 2009. Utilizamos para tal, os pressupostos teóricos da Análise de Discurso de linha francesa, oportunidade em que se constatou a articulação entre um tipo ideal de velhice (velhice positiva) e o consumismo em que as mulheres são instigadas a consumirem produtos diversos, valores para mascarar os sinais de envelhecimento e manterem a juventude eterna.

palavras - chave

Mulher. Envelhecimento. Discurso Midiático.

Nas últimas décadas, assistimos a uma explosão do envelhecimento demográfico no mundo. No Brasil, segundo os dados colhidos pelo IBGE, em 2010, 10,8 \% ${ }^{3}$ da população (20,5 milhões) possuía mais de 60 anos, sendo as mulheres a maioria. Esta redefinição na pirâmide etária tem corroborado

1 Discente do Curso de Ciências Sociais. Integrante do Programa Institucional de Bolsas de Iniciação Científica (PIBIC/UEMS-FUNDECT). E-mail: malheiros1985@hotmail.com

2 Possui graduação em Letras pela Faculdade de Ciências e Letras Urubupungá. Especialização em Língua Portuguesa pela Universidade Federal do Mato Grosso do Sul (UFMS/CEUL). Mestrado em Linguística Aplicada pela Universidade Estadual de Campinas (UNICAMP). Doutorado em Letras pela Universidade Estadual Paulista (UNESP) e pós-doutorado pela UNICAMP/Campinas. Professora adjunta da Universidade Estadual do Mato Grosso do Sul (UEMS). Docente do Mestrado em Educação e Letras da UEMS. Pró-reitora de Ensino nesta mesma instituição. E-mail: silvaneafreitas@hotmail.com 3 Fonte: <http://g1 globo.com/brasil/noticia/2012/04/em-50-anos-percentual-de-idosos-mais-quedobra-no-brasil.html>. Acesso em: 8 jan. 2013. 
para o surgimento de novas formas de sociabilidade, assim como para a construção de uma nova imagem do processo de envelhecimento.

A construção de novas concepções sobre a velhice ganhou força principalmente com o advento da terceira idade, que se opõe à velhice estigmatizada, oferecendo todo um aparato institucional/tecnológico, visando ao bem-estar dos indivíduos nesta fase da vida, se antes a velhice era concebida como um período de sucessivas perdas, com a terceira idade, ela passa a ser entendida como uma fase a ser aproveitada.

Os símbolos da velhice foram invertidos, assumindo novas qualificações: "melhor idade", "idade do lazer". Da mesma forma, inverteram-se as representações sobre a aposentadoria, que deixou de ser um momento de repouso para tornar-se um período de atividade, lazer, realização pessoal. Com a terceira idade, não se trata mais, apenas, de resolver os problemas econômicos dos idosos, mas de proporcionar cuidados culturais e psicológicos, reconfigurando, assim, os conceitos e concepções do envelhecimento (DEBERT, 2006).

Assim, a ideologia da terceira idade traduz-se no comprometimento dos indivíduos em atividades motivadoras, estilos de vida e consumo adequados na conquista do bem-estar. No entanto, esta nova visão da velhice, na perspectiva de Debert (1999), tem instado os indivíduos a suporem que boa aparência é igual a bem-estar, que viverão mais, aqueles que conservarem seus corpos com dietas, exercícios e outros cuidados. A autora, ainda, acrescenta que disciplina e hedonismo tem se traduzido na essência da velhice.

As mulheres estão mais comprometidas com esta ideologia da velhice ativa, como afirma Alda Brito da Motta (1999, p. 208), "as mulheres dão muito do tom social que assumem os grupos da terceira idade", já os homens, estão mais envolvidos em grupos de aposentados, afirma a autora, o que não os exclui de maneira alguma da influência dos pressupostos da terceira idade.

Na verdade, a partir da década de 1990, assistimos de forma, cada vez mais intensa, a um movimento que impõe um novo modelo de padronização para o comportamento e os corpos de homens e mulheres. Como afirmam Rachel Soihet e Maria Izilda Matos (2003), o corpo tornou-se objeto de exposição, desejo e interferências. O corpo tornou-se um "corpo-produto" que deve atender às exigências do mercado de acordo com o desejo do consumidor.

Todo este movimento de redefinição de condutas tem como pano de fundo a emergência de discursos que regulam, normalizam e instauram saberes, que produzem "verdades", assim, em certa medida, estas novas instituições e práticas acabam fabricando determinados tipos de sujeitos.

A partir do exposto, neste trabalho, temos a pretensão de discutir a questão da velhice, mais especificamente a velhice feminina, a partir das 
representações suscitadas pelos discursos produzidos pelas instâncias midiáticas, pois entendemos que os discursos midiáticos, devido a sua amplitude de propagação e veiculação, acabam corroborando na construção de identidades, visto que estas devem ser entendidas como construções discursivas.

Assim, analisamos um texto informativo que contém argumentos desta "nova velhice" presente na revista Veja, do mês de julho de 2009 (ed. 2121), com o fito de compreender que imagem e quais os valores estão sendo veiculados pela revista citada. Utilizamos para tal, os pressupostos teóricos da Análise de Discurso de linha francesa (AD), pois segundo esta perspectiva teórica, os dados são analisados, interpretados, levando em conta não só a materialidade linguística, mas a sua exterioridade, que é fundamental no processo de significação, ou seja, o sócio-histórico.

\section{Discurso e Linguagem}

A linguagem se configura como uma instituição social, um instrumento de mediação entre o homem com outros homens e o homem e a natureza, assim todo ato de linguagem deve ser concebido como um conjunto de significações que falam o mundo, por meio de determinadas condições (CHARAUDEAU, 2010).

Como argumenta Charaudeau (2006), a linguagem não faz referência apenas a um sistema de signos, mas também a um sistema de valores que condicionam o uso desses signos em determinadas circunstâncias de comunicação. Trata-se, assim, da linguagem enquanto ato de discurso, que aponta para o modo pelo qual se organiza a circulação da fala numa dada comunidade social ao produzir sentido. Desse modo, pode-se dizer que "todo discurso é um testemunho das especificidades culturais de cada país" (CHARAUDEAU, 2010, p. 8).

Assim, podemos afirmar que o discurso não é a língua, embora seja por meio dela, que se fabrique o discurso, e este, por um efeito de retorno, modifica-a. A língua é voltada para sua própria estrutura que tem sua organização fixa em diversos sistemas que registram os tipos de relação que se instauram entre suas formas (morfologia), suas combinações (sintaxe), e o sentido (semântica). "Descrever a língua é, de um modo ou de outro, descrever regras de conformidade, a serem repertoriadas em gramáticas e dicionários" (CHARAUDEAU, 2006, p. 40).

Já o discurso, não está condicionado unicamente às regras de uso da língua. Na verdade, este resulta de uma combinação das circunstâncias 
em que se fala ou escreve (identidade daquele que fala e daquele a quem se dirige, a relação de intencionalidade que os liga e as condições físicas da troca) com a maneira pela qual se fala. Pode-se dizer que é "a imbricação das condições extradiscursivas e das realizações intradiscursivas que produz sentido. Descrever sentido de discurso consiste, portanto em proceder a uma correlação dentre dois pólos" (CHARAUDEAU, 2006, p. 40).

O sentido discursivo nunca é dado a priori, ele é antes, construído pela ação linguageira do homem em situação de troca social. Para Patrick Charaudeau (2006), este se constrói ao término de um duplo processo de semiotização: de transformação e transação.

O processo de transformação consiste em transformar o mundo a "significar" em um mundo "significado", estruturando-o, segundo certo número de categorias, já o processo de transação, consiste para o sujeito produtor do ato de linguagem, em dar uma significação psicossocial a seu ato, isto é, atribuir-lhe um objetivo em função de certo número de parâmetros: hipóteses acerca da identidade do outro, seu saber, sua posição social, seu estado psicológico, seus interesses etc.; assim é o processo de transação que comanda o de transformação e não o inverso (CHARAUDEAU, 2006).

A finalidade do homem, ao falar, não é a de recortar, descrever, estruturar o mundo; ele fala, em principio, para se colocar em relação com o outro, porque disso depende a própria existência, visto que a consciência de si passa pela tomada da consciência da existência do outro, pela assimilação do outro e ao mesmo tempo pela diferenciação com relação ao outro. A linguagem nasce, vive e morre na intersubjetividade (CHARAUDEAU, 2006, p. 41-42).

Portanto, todo discurso antes de representar o mundo, representa uma relação, ou para ser exato, representa o mundo ao representar uma relação. (CHARAUDEAU, 2006). Isso também é válido para o discurso de informação ao qual trataremos detalhadamente a seguir.

\section{Discurso Informativo}

Para entendermos as estratégias utilizadas na produção da informação midiática, antes devemos entender o funcionamento da máquina midiática, por meio de suas especificidades. Neste trabalho, ater-nos-emos, principalmente, a visão do teórico Patrick Charaudeau (2006, 2010), uma vez que sua teoria está mais em consonância com os objetivos desta pesquisa: análise de textos denominados informativos. 
Nosso quadro de referência teórica é um modelo de análise de discurso que se baseia no funcionamento do ato de comunicação, que consiste numa troca entre duas instâncias: de produção e de recepção. Assim, o sentido resultante do ato comunicativo depende da relação de intencionalidade 4 que se instaura entre essas duas instâncias. Isso determina três lugares de pertinência: o da instância de produção, submetida a certas condições de produção: o da instância de recepção, submetida a condições de interpretação; o texto como produto, que se acha, enquanto tal, submetido a certas condições de construção (CHARAUDEAU, 2006, p. 23-24, grifo nosso).

Assim no que tange à máquina midiática, a instância de produção é representada pelo produtor de informação (o aparato midiático e seus atores), a instância de recepção pelo consumidor da informação (telespectadores, ouvintes, leitores) e o produto é representado pelo texto midiático (artigo de jornal/revista, telejornal etc.) (CHARAUDEAU, 2006).

Esta distinção, proposta por Charaudeau, entre os três locais de produção de sentido, permite-nos explicar a informação como resultado de uma co-intencionalidade, ou seja, o sentido não depende apenas da intenção do produtor, nem apenas da intenção do receptor. Desse modo, "esses três lugares se definem, [. . . ] cada um em relação aos demais como num jogo de espelhos em que as imagens incidem umas sobre as outras"' (2006, p. 28).

Neste ínterim, é importante ressaltar que comunicar é sempre proceder a uma encenação, como no teatro, em que o diretor se vale de um cenário, do espaço cênico, da luz, dos atores, e do texto para produzir efeitos de sentidos, visando a um público-alvo, imaginado por ele. Do mesmo modo, o locutor - seja ao falar ou escrever - também se utiliza de dispositivos para produzir efeitos de sentido em seu interlocutor (CHARAUDEAU, 2010).

Todo discurso depende, para a construção de seu interesse social, das condições específicas da situação de troca na qual surge. Assim, a situação de comunicação fornece o quadro de referência aos indivíduos de uma dada comunidade social ao iniciarem uma comunicação. "A situação de comunicação é como um palco, com suas restrições de espaço, de tempo, de relações, de palavras, no qual se encenam as trocas sociais e aquilo que constitui o seu valor simbólico" (CHARAUDEAU, 2006, p. 67).

\footnotetext{
4 "Empregamos esta palavra com um propósito preciso, pois, não se trata apenas do conjunto das intenções comunicativas plenamente concebidas e voluntariamente transmitidas. Trata-se de um conjunto de intenções que podem ser mais ou menos conscientes, mas que são todas marcadas pelo selo de uma coerência psicossociolinguageira. Não queremos reduzir o ato de linguagem a um fenômeno que origina de uma única intenção consciente. Queremos ao contrário, tomá-la em sua totalidade, isto é, o ato de linguagem é permeável ao impacto do inconsciente e do contexto sócio-histórico. Intencionalidade é diferente de intenção e equivale ao termo projeto de fala" (CHARAUDEAU, 2010, p. 48).
} 
Essas restrições que surgem em dada situação de comunicação são reguladas pelo que o autor chama de "contrato de comunicação", de certa maneira, esse contrato sobredetermina os sujeitos da linguagem. Em relação à esfera midiática, temos que

A finalidade do contrato de comunicação [. . . ] se acha numa tensão entre duas visadas, que correspondem, cada uma delas, a uma lógica particular: uma visada de fazer saber, ou visada de informação propriamente dita, que tende a produzir um objeto de saber segundo uma lógica cívica: informar o cidadão; uma visada de fazer sentir, ou visada de captação, que tende a produzir um objeto de consumo segundo uma lógica comercial: captar as massas para sobreviver à concorrência (CHARAUDEAU, 2006, p. 86).

Essas duas visadas estão intimamente ligadas ao funcionamento das mídias de informação que operam segundo uma dupla lógica: uma lógica econômica que faz com que todo aparato midiático funcione como uma empresa, fabricante de um produto que ocupa determinada posição no mercado de bens de consumo; e uma lógica simbólica que faz com que as mídias de informação tenham por vocação corroborar na construção da opinião pública (CHARAUDEAU, 2006).

É importante esclarecer que a Informação é essencialmente uma questão de linguagem, e a linguagem não é transparente ao mundo, ela apresenta sua própria opacidade a partir da qual se constrói uma visão, um sentido particular de mundo. Assim, ao informarem, as mídias não "transmitem o que ocorre na realidade social, elas impõe o que constroem do espaço público" (CHARAUDEAU, 2006, p. 19).

Para o referido autor, o espaço público, enquanto realidade empírica, é heterogêneo, desdobrando-se em inúmeras práticas, sendo umas de linguagem, outras de ação, outras de trocas de organização e influência. Isso ocorre nos três âmbitos da sociedade, a saber: o político, o civil e o midiático. Essas esferas sociais acabam se influenciando, mutuamente, sem que se saiba qual delas domina. Desse modo, os atores sociais de cada uma delas constroem para si uma visão do espaço público, como uma representação que tomaria o lugar da realidade (CHARAUDEAU, 2006).

Atestando o exposto, Gregolin (2003) argumenta que o que "[...] os textos da mídia oferecem não é a realidade, mas uma construção que permite ao leitor produzir formas simbólicas de representação da sua relação com a realidade concreta" (p. 97). 
Diante do exposto, podemos afirmar que o universo da informação midiática é um universo construído. Para Charaudeau (2006), o acontecimento (notícia) se constrói por meio de uma tríade de critérios: o de atualidade, a informação midiática deve dar conta de uma temporalidade co-extensiva ao sujeito a ser informado; de expectativa, pois a informação midiática deve captar o interesse/atenção do sujeito alvo; e de sociabilidade, as mídias devem assegurar que o que surge no espaço público seja compartilhado, ou seja, que a visibilidade do acontecimento seja assegurada.

\begin{abstract}
O acontecimento não é jamais transmitido em seu estado bruto, pois, antes de ser transmitido, ele se torna objeto de racionalizações: pelos critérios de seleção dos fatos e dos atores, pela maneira de encerrá-los em categorias de entendimento, pelos modos de visibilidade escolhidos. Assim, a instância midiática impõe ao cidadão uma visão de mundo previamente articulada, sendo que tal visão é apresentada como se fosse a visão natural do mundo (CHARAUDEAU, 2006, p. 151).
\end{abstract}

As mídias, ao se colocarem a serviço da democracia, informando os cidadãos, não devem ser confundidas com a própria democracia, pois o efeito produzido pelas mídias, ao informarem, é o de espetacularização da democracia, como já vimos, o real não é refletido como num espelho, mas construído, muitas vezes, levando-se em conta apenas a lógica econômica do aparato midiático.

A ideologia do "mostrar a qualquer preço", do "tornar visível o invisível" e do
"selecionar o que é mais surpreendente" (as notícias ruins) faz com que se
construa uma imagem fragmentada do espaço público, uma visão adequada
aos objetivos das mídias, mas bem afastadas de um reflexo fiel. Se são um
espelho, as mídias não são mais do que um espelho deformante, ou mais
ainda, são vários espelhos deformantes ao mesmo tempo, daqueles que se
encontram nos parques de diversões e que, mesmo deformando, mostram,
cada um à sua maneira, um fragmento amplificado, simplificado, estereotipado
do mundo (2006, p.19-20).

Por isso, a importância de se entender o discurso midiático, para não se cair na armadilha das falsas aparências, pois em uma comunidade social, muitas vezes, são produzidos discursos pra justificar seus atos, mas não está dito que estes discursos revelam a verdade em si, em que muitas vezes são mascarados, pervertidos ou são revelados apenas em parte (CHARAUDEAU, 2006). 
Destarte, a análise de discurso, que propomos, assenta-se em um processo de interpretação que implique uma crítica social, não como ideologia - pois se a crítica fosse direcionada, a análise estaria comprometida - "mas como processo que faz descobrir o não dito, o oculto, as significações possíveis que se encontram por trás do jogo de aparências" (CHARAUDEAU, 2006, p. 29).

Neste sentido, Foucault (2008, p. 171) argumenta que "analisar o discurso é fazer com que desapareçam e reapareçam as contradições; é mostrar o jogo que nele, elas desempenham; é manifestar como ele pode exprimi-las, dar-lhes corpo, ou emprestar-lhes uma fugidia aparência".

O papel do analista é o de observar a distância, para tentar compreender e explicar como funciona a máquina de fabricar sentido social, engajando-se em interpretações cuja relatividade deverá aceitar e evidenciar. Apresentar como verdade absoluta uma explicação relativa e acreditar nela seria arrogância. Fazê-lo sem acreditar seria cinismo. Entretanto, entre arrogância e cinismo, há lugar para uma atitude que, sem ignorar as convicções fortes, procure compreender os fenômenos, tente descrevê-los e proponha interpretações para colocá-los em foco no debate social (CHARAUDEAU, 2006, p. 29).

Feitas as devidas colocações a respeito do discurso e suas relações, faz-se necessário entendermos as condições de produção do discurso da velhice, situar melhor esses discursos levando em conta as condições sócio-históricoculturais, para melhor apreensão dos efeitos de sentido presentes no artigo a ser analisado.

\section{As representações da velhice}

Nas sociedades modernas, a flexibilização das classificações das idades e o esmaecimento das fronteiras etárias tem sido o ponto nodal das relações geracionais em que as idades são apreendidas como etapas que definem estilos e modos de ser no mundo, com uma característica peculiar de valorização da juventude como padrão a ser estendido a outras faixas etárias, ocasionando um contraste com a velhice entendida a partir desta visão como algo que deve ser negado (BARROS, 2011).

Neste sentido, Alda Brito da Motta (1999) argumenta que idades e gerações são importantes fatores de organização social, entretanto, a condição etária e, principalmente, o envelhecimento, ainda figuram como mecanismos de separação e classificação de seres humanos. Para a referida autora, ser jovem 
ou ser velho é uma situação vivida, em parte, de maneira homogênea e, em parte, diferencialmente, dependendo de fatores como gênero e classe social.

Para Sibila (2011), com o aumento da expectativa de vida, novos tabus são construídos em relação ao envelhecimento, o corpo velho foi transformado em uma afronta, um sinal visível da derrota do ser humano na luta pela permanência do aspecto juvenil, assim "a velhice é um direito negado ou algo que deveria permanecer oculto [...]" (p. 83).

Nesse contexto, as mulheres são os principais alvos de estratégias articuladas por algumas áreas das ciências médicas e pela indústria da beleza para retardar o envelhecimento ao máximo, por meio de práticas que visam à manutenção do corpo e da mente.

Isso porque "as interferências no corpo envelhecido e o aprendizado de um modo de viver a velhice a partir da ideia de atividade e de responsabilidade pessoal constituem as bases da ideologia da terceira idade" (BARROS, 2011, p. 49). A terceira idade poderia então ser entendida como uma justificativa moral, para a reprivatização da velhice, que para Debert (1999) corresponde à responsabilização dos indivíduos por seu próprio cuidado e bem-estar.

Oenvelhecimento, na atual conjuntura, "torna-se realmente uma questão global e particularmente feminina” (MOTTA, 1999, p. 208). É especialmente sobre o corpo feminino que são direcionados investimentos médicos estéticos acentuados, dando continuidade ao processo de medicalização que é incidido sobre a mulher desde muito cedo (BARROS, 2011).

Se antes os corpos eram submetidos a uma forma específica de dominação, o poder disciplinar, demonstrado por Foucault em sua genealogia do poder, onde a "disciplina fabrica[va] [...] corpos submissos e exercitados, corpos dóceis"(1987, p. 119). Hoje poderíamos dizer concordando com o filósofo Peter Pelbart que houve uma inversão, os sujeitos agora "voluntariamente" decidem se submeter a uma espécie de ascese, seguindo ora um preceito científico, ora um preceito estético. Se por um lado, isso revela um desejo do indivíduo de se adequar às normas científicas da saúde: longevidade, equilíbrio. Por outro, seria uma maneira de se adequar o corpo à cultura do espetáculo, seguindo o modelo de celebridade (PELBERT, 2007).

Entendemos que na era do "culto ao corpo, e da espetacularização da sociedade, os corpos são instados a se converter em imagens com certas características pré-definidas, desencantando-os, assim, de seus potenciais simbólicos e os limitando a se exprimir dentro dos parâmetros ideais dos manuais da boa aparência (SIBILA, 2011). 
Nesta "sociedade do espetáculo" que insta a obter celebridade midiática para poder "ser alguém", e que avalia o que cada um é em função do que se vê na sua superfície corporal, a velhice é um direito negado [ . . . ] Em meio a uma crescente tirania das aparências juvenis, a velhice é censurada como algo obsceno e vergonhoso, que deveria permanecer oculto, fora da cena, sem ambicionar a tão cotada visibilidade (SIBILA, 2011, p. 94).

Os discursos midiáticos têm voltado todos seus esforços para divulgar as novas técnicas de rejuvenescimento, com o intuito de mostrar que, na atual conjuntura, rugas e flacidez não são aceitáveis, são tidas como indícios de lassitude moral, na verdade uma negligência por parte dos indivíduos que se negaram a fazer uso de cosméticos e procedimentos cirúrgicos, sendo as mulheres as principais vítimas desse tipo de imposição. Nota-se que a juventude perde conexão com uma faixa etária específica e torna-se um valor, um bem que pode ser adquirido, com esforço e investimento (DEBERT, 1999).

Bauman, em seu estudo sobre a sociedade de consumo, mostra que os indivíduos ao recorrerem aos produtos e serviços oferecidos pela indústria da beleza, não querem apenas

Remover uma cicatriz ou alcançar uma forma ideal negada pela natureza, ou pelo destino, mas para ficar em dia com padrões que mudam com rapidez, manter o próprio valor de mercado e descartar uma imagem que perdeu sua utilidade o seu charme, de modo que uma nova imagem pública seja colocada em seu lugar - num pacote que inclui (espera-se) uma nova identidade e (com certeza) um novo começo (BAUMAN, 2008, p. 130).

Essa nova imagem que se tem difundido da velhice, sobretudo, pelas instâncias midiáticas, acaba por encobrir os problemas próprios da idade mais avançada. Dessa maneira, "o corpo ingovernável, as traições que o corpo faz às vontades individuais são, antes, percebidas como frutos de transgressões conscientemente impetradas, abominações da natureza humana" (DEBERT, 1999, p. 22).

Mediante essas cobranças para demonstrarem jovialidade, sobretudo, as mulheres passam por um processo de subjetivação, entendem que para serem aceitas, devem estar de acordo com os padrões vigentes; negando, assim, o próprio eu; obscurecendo seus atributos e sua identidade, uma vez que a sociedade do espetáculo exige que todos sejam jovens, bonitos, com aparência saudável. Assim, o idoso passa a se preocupar com a imagem que a sociedade/o outro faz de si, passando a cobrar mais de si próprio, pois ele mesmo não se pode imaginar fora desses padrões pré-estabelecidos. 
Para análise, foi escolhida a edição (2121) da revista Veja (http://veja.abril. com.br/150709/sem-idade-p-062.shtml), que trouxe um encarte especial com várias páginas sobre a velhice, dentre os vários artigos presentes nessa edição, foi escolhido o artigo denominado "Os sem idade desafiam o calendário", apesar de não ser exclusivamente voltado para o público feminino, o referido texto se vale das representações de duas mulheres na construção de sentido.

Assim sendo, objetivamos, nesta pesquisa, analisar o jogo de imagens e valores veiculados no referido artigo. A escolha da Revista Veja para análise se deu, tendo em vista que ela se configura como umas das revistas de grande influência no cenário brasileiro, sendo uma das mais vendidas, por isso, corroborando na determinação de valores e crenças de grande parte da população.

Para a análise do referido discurso, presente na revista Veja, foi necessário explorarmos tanto os aspectos imagéticos, quanto verbais, o que possibilitou uma melhor apreensão dos efeitos de sentido que esta reportagem produz.

Para produzir os efeitos de sentido esperados, Veja, nessa edição, se utiliza já na capa de um jogo de imagens, usando uma foto grande da metade do rosto de duas mulheres, dando a impressão que se complementam, provocando a ilusão de que não há diferença entre elas, porém uma mulher tem 25 anos (a filha) e a outra 52 anos (a mãe). Esse jogo de imagens, aliado ao enunciado "Geração sem idade" em letras grandes no meio dos rostos que se completam, se articulam na medida em que direcionam o leitor ao tema que Veja abordará nas 36 páginas da referida edição, "como viver mais, melhor e sem os efeitos do tempo".

Por meio do enunciado do título do artigo analisado "os sem idade desafiam o calendário", podemos observar um movimento que há alguns anos ganha força, o de separar os indivíduos do signo etário, ou seja, o número que representa socialmente o quanto o indivíduo viveu e, visto que os signos são ideológicos e não existem apenas como parte de uma realidade, mas também refletem outra (BAKHTIN, 2010). Isso nos leva a afirmar que o signo "etário" na atual conjuntura, acaba por evidenciar como um "estigma": a degenerescência, a proximidade do ser humano com a finitude. Por isso, Veja usa esta expressão "os sem idade", libertando, assim, seus interlocutores deste signo que os condiciona a uma existência fadada à decadência, tanto física quanto social, e lhes dá a oportunidade de uma vida "atemporal", ou seja, pode-se permanecer jovem em qualquer fase da vida. 
Já no corpus do texto, mais uma vez, Veja se vale da imagem das duas mulheres, porém agora de corpo inteiro, a ênfase é na mulher de 52 anos, que é demonstrada como sendo muito jovial e ativa, que compartilha dos mesmos gostos da filha "temos algumas peças idênticas no guarda roupa, apesar de Dani policiar meus decotes”, afirma Mara Lúcia, a mãe da modelo Daniela Sarahyba. Veja, com esse enunciado, segue a linha traçada no início, ou seja, a de desvincular totalmente a relação de idade com o tempo (cronológico) e dar uma nova significação para o termo "idade", como fica claro nesse outro enunciado, "[...] a idade real se traduz, pelo estilo de vida, e não pelo calendário".

Desse modo, ao desarticular a relação entre idade e tempo, e (re) significá-la, articulando-a agora com o estilo de vida, Veja propõe um novo olhar acerca do envelhecimento, bem como uma crítica às categorias cristalizadas no imaginário social, principalmente, as que classificam os indivíduos conforme sua faixa etária, restringindo de certa forma a sociabilidade entre as gerações.

Para validar seus argumentos, Veja utiliza-se do testemunho de Mãe e filha, representantes fidedignas da quebra do "paradigma etário" como fica evidente no enunciado: "Mara e Daniella, apesar da diferença de geração, compram roupas nas mesmas lojas, costumam viajar juntas e não raro frequentam as mesmas festas".

O uso de testemunhos é uma estratégia muito usada pelas mídias, pois testemunhar é uma forma de enunciação que revela, ou pelo menos confirma, a existência de uma realidade com a qual o enunciador teve contato, nas palavras de Charaudeau (2006, p. 224), quem testemunha é "levado a dizer o que viu, ouviu ou tocou, sem análise, nem julgamento [. . . ] o que lhe confere os traços da pureza e da autenticidade. A palavra de testemunho instaura o imaginário da "verdade verdadeira".

Assim, ao se valer do testemunho de um anônimo ou de um sujeito com certa notoriedade, a mídia pretende criar uma identificação entre a testemunha e a categoria a qual ela representa por meio de um simulacro. No entanto, além de uma crítica à estrutura etária estigmatizante, entendemos que o discurso de Veja acaba se coadunando com o discurso dominante, o qual tem transformado o movimento denominado "terceira idade" em um nicho mercadológico, sobretudo, por meio do argumento de que é possível ser jovem em qualquer fase da vida, desde que se adquiram certos produtos e serviços, como podemos observar neste enunciado "Minha mãe é jovial e ativa o que faz dela uma ótima companhia para qualquer hora". 
Assim, tanto os argumentos utilizados por Veja, quanto as imagens de Mara Lúcia - imagem perfeita aos argumentos da nova velhice - acabam se traduzindo em um reforçador desta velhice mercadológica, mesmo que esta não tenha sido a pretensão. Dizemos isso, pois logo após o artigo, Veja apresenta em duas páginas um anúncio enorme do produto "Chronos" da Natura - anti-sinais que promete livrar as mulheres das imperfeições ocasionadas pelo processo de envelhecimento - articulando, deste modo, os sentidos construídos com a imagem de Mara Lúcia (jovial e ativa) ao produto oferecido nas páginas seguintes, produto este, que promete devolver a jovialidade da pele, quiçá da alma.

Esta atitude de Veja demonstra a contradição inerente ao aparato midiático que se divide entre sua lógica simbólica e econômica, muitas vezes, subsumindo a informação ao mercado de bens de consumo.

Além disso, quando Veja desloca o termo idade de sua relação com o tempo, ela o (re)significa, construindo uma nova relação, deslocando seu discurso para questões identitárias, ou seja, está trabalhando na produção e reprodução de identidades, visto que a identidade se configura como uma construção discursiva, e "na sociedade contemporânea, a mídia é o principal dispositivo discursivo [. . .]. É ela, em grande medida, que formata a historicidade que nos atravessa e nos constitui, modelando a identidade [. . . ]" (GREGOLIN, 2007, p. 16).

Nesse sentido, Gregolin argumenta que

\begin{abstract}
Ao mesmo tempo, o trabalho discursivo de produção de identidades desenvolvido pela mídia cumpre funções sociais básicas tradicionalmente desempenhadas pelos mitos - a reprodução de imagens culturais, a generalização e a integração social dos indivíduos. Essas funções são asseguradas pela ampla oferta de modelos difundidos e impostos socialmente por processos de imitação e formas ritualizadas. Esses modelos de identidades são socialmente úteis, pois estabelecem paradigmas, estereótipos, maneiras de agir e pensar que simbolicamente inserem os sujeitos na "comunidade imaginada". A sofisticação técnica produz uma verdadeira saturação identitária pela circulação incessante de imagens que têm o objetivo de generalizar os modelos. A profusão dessas imagens age como um dispositivo de etiquetagem e de disciplinamento do corpo social (2007, p. 17-18).
\end{abstract}

Essa realidade demonstrada por Gregolin também está presente na obra do sociólogo Zygmunt Bauman (1998), ao afirmar que em uma sociedade voltada para o consumo, as identidades não são fixas, permanecem instáveis, flutuantes, na verdade, funcionam como máscaras que podem ser 
adotadas ou descartadas como uma troca de roupa. Podemos dizer que em uma sociedade de consumo como a nossa, as identidades são transformadas em bens de consumo, materializando-se nos produtos e serviços oferecidos pelo mercado.

Quando os indivíduos consomem, eles não compram apenas um produto, mas cada produto traz consigo uma identidade agregada, o que estimula e ao mesmo tempo causa uma constante insatisfação, visto que seus desejos jamais são satisfeitos, pois sempre surge no mercado uma nova identidade, com novas promessas e ilusões. Dizemos ilusões, porque, para estimular o consumo, faz-se necessário uma encenação por parte dos vendedores, que simulam um conto de fadas, onde os consumidores fazem a vez de protagonistas, sem perceberem que na verdade são figurantes. O verdadeiro dono da cena é o "mercado de consumo", como evidenciado neste enunciado pronunciado pela estilista Isabella Giobbi "nossas vendedoras são orientadas para tratar a compradora [acima dos 50] pelo nome ou por você. As mulheres vão fazer compras para se sentir bem, e não para se sentir velhas".

Nesta busca constante dos sujeitos por afirmação social e participação em determinados grupos, eles acabam por se submeterem a um jogo fetichista proporcionado pelo mercado de consumo, aceitam ser usados e aviltados em sua subjetividade, mesmo que inconscientemente.

Diante dos fatos mencionados, podemos dizer que nesta reportagem analisada da Revista Veja, há uma articulação no campo das materialidades linguística e imagética, na medida em que ambas obedecem ao mesmo direcionamento (o ditado por Veja). Desse modo, o sujeito independente da ordem que olhe, obterá os mesmos efeitos de sentido, ou seja, que a velhice pode e deve ser retardada/camuflada ao máximo, que se pode/deve manter a beleza e aproveitá-la em plenitude mesmo em idade avançada.

Entendemos que os discursos produzidos tendem a criar no imaginário social a ideia de juventude eterna e, por conseguinte, incita os sujeitos a buscarem este bem, porém para o conseguirem, devem aderir a certo estilo de vida e consumo. As pessoas acabam acreditando que a mídia, considerada informativa, pretende apenas informá-las, pois o aparato midiático pressupõe imparcialidade, e não percebem que estão sendo levadas a consumirem os produtos, as crenças e os valores juntos com aquela informação. 
Consideramos que nesta reportagem há uma articulação entre a lógica simbólica e a econômica do aparato midiático (revista Veja), aonde as informações prestadas aos cidadãos subsumem-se ao produto oferecido nas páginas seguintes, os sentidos construídos a partir da imagem da mulher de 52 anos (jovial e ativa), se encaixam de maneira perfeita ao produto oferecido em seguida (Chronos), na verdade, a imagem de Mara Lúcia, torna-se um incentivo ao consumo do produto, que dentre outras coisas promete proporcionar a jovialidade presente na mesma.

Assim, apesar de pretender-se crítica, a reportagem acaba funcionando como um reforçador desta "nova velhice", quem tem em suas bases a ideologia da juventude eterna. Com isso, os indivíduos mais afetados por estes discursos têm sido as mulheres, que passam a negar sua velhice, adotando estes estilos de vida, passando a consumir produtos e serviços que prometem, ao mesmo tempo, a tão desejada juventude, como a inserção em determinadas comunidades imaginadas.

\section{Os comportamentos saudáveis que implicitamente orientam ao rejuvenesci- mento como condição de aceitação e reinserção social constituem um terreno onde realmente transitam mais intensamente as mulheres, em cuja busca do corpo saudável está imersa também a histórica busca da beleza como legiti- mação de presença social (MOTTA, 2012, p. 12).}

Diante do exposto, podemos afirmar que o que Guy Debord expôs na década de 60, do século passado, acerca da sociedade do espetáculo, seria mais apropriado ao período em que vivemos, em que o parecer tornou-se mais importante que o ser, obrigando inúmeros indivíduos a procurarem a estratégia do disfarce para serem aceitos e se aceitarem. Talvez, o disfarce tão presente em nossa época, seja simplesmente a subsunção dos indivíduos a uma sociedade que substituiu o real pelo seu simulacro. 


\section{abstract}

This study aimed to discuss the old women, through the analysis of an article in Veja magazine of August 2009. We used to do such, the theoretical analysis of French Discourse, at which time it was found a link between an ideal type of aging (positive aging) and consumerism in which women are urged to consume various products, amounts to mask the signs of aging and maintain eternal youth.

keywords

Women. Aging. Media Discourse.

referências

BAKHTIN, Mikhail (Volochínov). Marxismo e filosofia da linguagem. São Paulo: Hucitec, 2010.

BARROS, Mirian Moraes Lins de. A velhice na pesquisa socioantropológica brasileira. In: GOLDENBERG, Mirian (Org.). Corpo, envelhecimento e felicidade. Rio de Janeiro: Civilização Brasileira, 2011. p. 45-64.

BAUMAN, Zygmunt. O mal-estar da pós-modernidade. Rio de Janeiro: Zahar, 1998.

Vida para o consumo: a transformação das pessoas em mercadoria. Rio de Janeiro: Zahar, 2008.

BEGUOCl, Leandro et al. Como viver mais e melhor. Veja, Edição 2121, ano 42, n. 28, 2009, p. 62-114.

CHARAUDEAU, Patrick. Discurso das Mídias. São Paulo: Contexto, 2006.

2010.

Linguagem e discurso: modos de organização. 2. ed. São Paulo: Contexto,

DEBERT, Guita Grin. A reinvenção da velhice: socialização e processos de reprivatização do envelhecimento. São Paulo: Editora da Universidade de São Paulo, Fapesp, 1999.

. Velhice e tecnologias do rejuvenescimento. In: GOLDENBERG, Mirian (Org.). Corpo, envelhecimento e felicidade. Rio de Janeiro: Civilização Brasileira, 2011. p. 65-82.

FOUCAULT, Michel. Arqueologia do saber. 7. ed. Rio de Janeiro: Forense Universitária, 2008.

. Vigiar e Punir: História da violência nas prisões. Petrópolis: Vozes, 1987. 
GREGOLIN, Maria do Rosário Valencise. Análise do discurso e mídia: a (re)produção de identidades. Comunicação, mídia e consumo, São Paulo, v. 4, n. 11, 2007, p. 11 25. Disponível em: <http://revistacmc.espm.br/index.php/revistacmc/issue/view/11/ showToc>. Acesso em: 14 abr. 2012.

O acontecimento discursivo na mídia: metáfora de uma breve história do tempo. In: GREGOLIN, Maria do Rosário Valencise (Org.). Discurso e mídia: a cultura do espetáculo. São Carlos: Claraluz, 2003. p. 95-110.

MATOS, Maria Izilda S. de; SOHET, Rachel (Org.). O corpo feminino em debate. São Paulo: Unesp, 2003.

MOTTA, Alda Britto da. As dimensões de gênero e classe social na análise do envelhecimento. In: DEBERT, Guita Grin (Org.). Cadernos Pagu: Gênero em gerações, Campinas, n. 13, p. 191-221, 1999. dez. 2012

O final da vida no século XXI. Mediações, Londrina, v. 17, n. 2, p. 9-25, jul./

PELBART, Peter Pál. Biopolitica. Revista Sala Preta, São Paulo, n. 7, 2007, p. 57-66. Disponível em: <http://umw.eca.usp.br/salapreta/sp07.htm>. Acesso em: 14 abr. 2012.

SIBILA, Paula. A moral da pele lisa e a censura midiática da velhice: o corpo velho como uma imagem com falhas. In: GOLDENBERG, Mirian (Org.). Corpo, envelhecimento e felicidade. Rio de Janeiro: Civilização Brasileira, 2011. p. 83-108.

Recebido: 25/04/2012

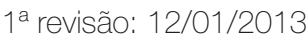

Aceite Final: 28/01/2013 